\title{
ANNA NAVA, BALUARTE DA ESCOLA ANNA NERY (ANOS 1940/1970)
}

\author{
Anna Nava, Escola Anna Nery's (Anna Nery's School) \\ bastion (1940s/1970s)
}

\author{
Anna Nava, baluarte de la Escuela Anna Nery \\ (años 1940/1970)
}

Suely de Souza Baptista ${ }^{1}$

leda de Alencar Barreira²

\section{RESUMO}

Pesquisa histórico-biográfica que apresenta a trajetória de vida da enfermeira Anna Jaguaribe da Silva Nava (1910-2005). No período no qual transcorreu sua vida, o panorama nacional foi, por várias vezes, radicalmente alterado. Sua atuação como professora da Escola Anna Nery vai de 1940 a 1977. 0 texto foi construído a partir do depoimento oral da protagonista, concedido em 2003 e por ela doado ao Centro de Documentação da Escola de Enfermagem Anna Nery. 0 presente trabalho tem como interesse principal o entrelaçamento da história de vida desta personagem com as gestões de três diretoras da EAN, desde a época em que a Escola Anna Nery era padrão oficial para o ensino de enfermagem no país até o período da vigência da Lei 775/ 49.

Palavras-chave: Enfermagem. História da Enfermagem. Biografia. Brasil.

\begin{abstract}
A historical biographical research that presents nurse Anna Jaguaribe da Silva Nava's life path (1910-2005). During the period in which her life elapsed, the national panorama changed radically for many times. Her performance as Escola Anna Nery's professor took place from 1940 to 1977 . The text was built over the protagonist's own oral report, given in 2003 and donated by herself to the Documentation Center of Anna Nery Nursing School. The present work focuses mainly at the intertwinement of this character's life story with the management of three EAN's directors, beginning from the time Escola Anna Nery was the official standard in the country for nursing teaching until when the Law775/49 was in force.
\end{abstract}

Keywords: Nursing. Nursing History. Biography. Brazil

\section{Resumen}

Investigación histórica y bibliográfica que presenta la trayectoria de vida de la enfermera Anna Jaguaribe da Silva Nava (1910-2005). Durante el periodo de su vida, el panorama nacional sufrió, en diversas ocasiones, cambios radicales. Fue Profesora de la Escuela Anna Nery entre 1940 y 1977. El texto fue elaborado a partir del testimonio oral de la protagonista concebido en 2003, y donado por ella al Centro de Documentación de la Escuela de Enfermería Anna Nery. Este trabajo tiene como centro de interés principal el entrelazamiento de la historia de vida de este personaje y las gestiones de tres directoras de la EAN. Incluye la época en que la Escuela Anna Nery fue el estándar oficial para la enseñanza de enfermería en el país hasta el periodo de la vigencia de la Ley $775 / 49$.

Palabras clave: Enfermería. Historia de la Enfermería. Biografia. Brasil

'Doutora em História da Enfermagem. Professora Visitante da Faculdade de Enfermagem da Universidade do Estado do Rio de Janeiro (FE/UERJ). Membro Fundador do Núcleo de Pesquisa de História da Enfermagem Brasileira (Nuphebras). Pesquisadora CNPq. Brasil. E-mail: suelybaptista@openlink.com.br, ${ }^{2}$ Doutora em História da Enfermagem. Professora Permanente do Programa de Pós-Graduação da Escola de Enfermagem Anna Nery/UFRJ. Membro Fundador do Nuphebras. Pesquisadora CNPq. Brasil. E-mail: iedabarreira@openlink.com.br 


\section{INTRODUCÃO}

A vida de Anna Nava abrange o período de 1910 a 2005, portanto quase cem anos. Sua formação familiar e escolar deuse quase toda no estado de Minas Gerais. Primeiro, na Juiz de Fora do tempo da Velha República', depois em Belo Horizonte (BH), até o início do Estado Novo, quando foi estudar Enfermagem no Rio de Janeiro, à época capital federal, onde radicou-se após a formatura. Sua atuação como enfermeira e professora da Escola Anna Nery (EAN) vai de 1940 a 1977, estendendo-se da gestão da última diretora americana e passando pelas gestões de cinco diretoras brasileiras. Tomamos como centro maior de interesse sua percepção e apreciação da gestão e personalidade de três diretoras da EAN: primeiro, da americana Bertha Lucille Pullen, em sua segunda gestão (1934-1938), e da fluminense Laís Netto dos Reys (gestão: 1938-1950), que em conjunto, abarcam a maior parte do período em que a EAN foi o padrão oficial para o ensino da enfermagem no Brasil (1931-1949); e depois da também fluminense Waleska Paixão (1950-1968), cuja gestão coincidiu com a vigência da Lei 775/49.

0 presente trabalho tem como objetivos: descrever a formação do habitus primário e do profissional de Anna Nava; analisar a trajetória profissional de Anna Nava; discutir sua posição e seus pontos de vista sobre a enfermagem.

\section{ABORDAGEM TEÓRICO-METODOLÓGICA}

A fonte primária deste estudo é o depoimento oral de Anna $\mathrm{Nava}^{4}$, concedido a Suely de Souza Baptista nos meses de setembro e outubro de 2003, mediante a realização de três entrevistas de cerca de três horas cada uma. 0 depoimento e sua respectiva transcrição foram por ela doados ao Centro de Documentação da Escola de Enfermagem Anna Nery/UFRJ (Cedoc/EEAN/UFRJ). Também foi utilizado o dossiê da aluna Anna Nava (1937-1940), encontrado no Cedoc/EEAN//UFRJ. Esta produção intencional ocorreu pela recriação de experiências, a partir da interação entre entrevistadora e entrevistada. Como nos lembra Valentina da Rocha Lima ${ }^{5: 15}$, estes dois sujeitos,

diferentes por definição e diferentes pelo que sabem, estabelecem entre eles uma relação intersubjetiva, que é singular. Nela define-se o pesquisador como sujeito ao perguntar e assim induzir a lembrança. Mas nela define-se também o narrador como sujeito, porque é o que ele sabe (e como o memora) o que interessa, é a sua história pessoal que se refaz. Porém, as narrativas, no momento em que se produzem, não são mais a história vivida, dado que o vivido não pode ser recuperado sequer por quem o viveu. Trata sim de reviver, de reconstituir, de recriar. Deste modo, ao contar sua vida, o narrador executa um trabalho: o de resgatar 0 passado, conferindo-lhe significados.
A fala de Anna Nava evidencia a dubiedade temporal a que se refere a autora: ora fala a jovem Anna, ora fala a professora já madura, e ora fala a anciã que concede a entrevista, fazendo ressuscitar um mundo e situando-se nele; avaliando-o retrospectivamente e situando-se já fora dele. À evocação do vivido, Anna Nava reflete sobre sua experiência, que é contada no modo como ela pensa tê-la vivido, e também no modo como ela compreendia o vivido ao gravar seu depoimento, apenas dois anos antes de sua morte. No caso particular de Anna Nava, pessoa possuidora de dotes de inteligência e que, por formação, por gosto e por profissão, interessava-se pelas coisas da cultura, da literatura e das artes, estes trabalhos da memória se fizeram com extrema acuidade e sensibilidade.

Os achados foram analisados e discutidos tendo referência o pensamento de Pierre Bourdieu aplicado ao campo educacional ${ }^{2}$, com destaque para o conceito de habitus, como conjunto de disposições para a ação, que corresponde à história incorporada, princípio gerador do que fazemos ou das respostas que damos às contingências sociais ${ }^{3}$.

Vale dizer que este estudo não tem como propósito oferecer um exemplo moral, mas sim apresentar a visão singular de uma professora da EAN sobre o universo em que atuou, e mais, criar fontes primárias para outros estudos. A narrativa que se segue é feita ora na terceira pessoa, ora damos a palavra à depoente.

\section{Origens, infância e adolescência}

Anna Jaguaribe da Silva Nava, filha de José da Silva Nava e de Diva Jaguaribe Nava, nasceu no dia 17 de maio de 1910, na cidade de Juiz de Fora ${ }^{1}$, situada na Zona da Mata de Minas Gerais. 0 pai de Anna não tinha riqueza, mas seu padrasto custeou seus estudos. Ele fez o curso de farmácia junto com o de medicina. Depois de muitas lutas, ele passou em dois concursos no Rio: para médico legista da polícia e para médico sanitarista. Doutor José foi chefe do Posto de Saúde do Méier e teve uma farmácia neste mesmo bairro, a Farmácia Nava.

A menina Anna nasceu nesse período "de mais abastança". Contudo, seu pai faleceu quando ela tinha pouco mais de um ano de idade e sua mãe estava esperando sua filha caçula, Maria Luiza. Quando d. Diva ficou viúva, e voltou para a casa dos pais, em Juiz de Fora, deixou de ser uma "sinhá pequena", com todos os privilégios correspondentes a uma jovem senhora. Seu pai (avô de Anna), Alencar de mãe e Jaguaribe de pai, casara-se com a viúva de Henrique Guilherme Fernando Halfeld, fundador de Juiz de Fora. Mas quando eles perderam a fortuna, d. Diva mudou-se com as filhas para BH, capital do estado de Minas Gerais desde 1897, onde tinha um tio que era 0 responsável pela Comissão Construtora da Cidade.

Aos quinze anos de idade, Anna concluiu o curso secundário, no internato do Colégio Imaculada Conceição, fundamental para sua formação: eu era uma menina e foi onde eu aprendi que não é obrigatoriamente necessário haver injustiça no mundo. Depois, a jovem Anna ingressou na Escola Normal Modelo de 
Belo Horizonte, onde se diplomou professora, em 1929. Também estudou violino durante cinco anos, no Conservatório de Música, onde sua irmã estudava piano. Anna Nava recorda os tempos em BH: nós não fomos pioneiras de BH, mas ainda encontramos gente chorando porque a capital tinha mudado de Ouro Preto. Fizemos muito boas relações lá, muito boas amizades. Foi fantástica nossa vida em BH. Assim, tendo formado seu habitus no seio de uma família culta e bem relacionada, embora em dificuldades financeiras, e estudado em bons colégios, públicos e de elite, Anna Nava era portadora de um considerável capital social e cultural.

\section{De professora primária à enfermeira diplomada}

Depois de lecionar por mais de dez anos, em BH, Anna Nava, "animada por uma amiga", talvez como resultado de uma acomodação de sua percepção de si à sua avaliação das oportunidades então oferecidas às mulheres, decidiu estudar enfermagem. Em BH havia a Escola de Enfermagem Carlos Chagas, de orientação católica, dirigida por Laís Netto dos Reys (LNR), formada na turma pioneira da EAN ${ }^{6}$. Mas Anna Nava fazia certas restrições ao estilo dessa Escola: eu via na rua alunas e professoras de uniforme, os véus esvoaçando, eu não tinha vontade nenhuma; seu desejo era mais o de estudar na escola padrão oficial, na capital do Brasil. Ainda mais porque seu irmão, o médico e escritor Pedro Nava, que trabalhava com o sanitarista e cientista Evandro Chagas na Prefeitura do Distrito Federal, conhecera duas enfermeiras de "alto padrão".

Vale lembrar que Evandro Chagas era o primogênito de Carlos Chagas, o patrono da enfermagem brasileira. A aspiração da jovem Anna se tornou realidade por força do capital político de sua família, como ela comenta: eu tinha um amigo, na Secretaria de Educação de Minas Gerais, no gabinete do Cristiano Machado, ele terminou conseguindo que eu ficasse com meu emprego de professora, à disposição da Escola Anna Nery.

Em meados de 1937, ano em que a EAN ingressou na Universidade do Brasil (UB), Anna Nava, então com vinte e sete anos de idade, chegou ao Rio de Janeiro para estudar enfermagem. Como era portadora de capital institucionalizado, sob a forma de diploma de professora primária, foi isenta das provas de seleção, mas não do "exame social". A diretora da Escola era Miss Bertha Lucille Pullen, enfermeira norteamericana que estava cumprindo seu segundo mandato (1934$1938)^{7,8}$. Anna explica como vantajosa sua situação, em relação à maioria das candidatas:

no tempo das americanas, mandavam esperar a gente na estação e colocar nas pensões; porque ninguém podia ficarna Escola antes de ser aprovada no exame social. Mas eu fui para a casa de meus tios, e meu irmão José me levou à Escola, no dia do exame social.

0 exame consistia em uma arguição por pessoas ilustres ligadas à EAN, no seu caso: Edith de Magalhães Fraenkel (EMF), poderosa superintendente do Serviço de Enfermagem do Departamento Nacional de Saúde Pública (DNSP), Zaíra Cintra Vidal, chefe da Divisão de Ensino da EAN e um representante da Fundação Rockefeller, a qual patrocinara a criação da EAN e apoiava seu desenvolvimento ${ }^{9}$ : eles perguntaram o que eu fazia, o que me fez vir para a Escola, se eu conhecia alguém da Escola, quem se responsabilizaria por mim no caso de necessidade. Assim, esta prova, que a muitas pareceu um imenso obstáculo, foi encarada por Anna com a naturalidade inerente ao seu capital social.

Uma vez aprovada, Anna Nava passou a morar na bela residência da Escola, na Av. Rui Barbosa, $n^{\circ} 762$, na enseada de Botafogo, ex-hotel 7 de Setembro ${ }^{10}$, onde eram oferecidos às alunas um ambiente refinado e modelos exemplares. Esta intenção da Escola de atualizar e adequar o habitus secundário trazido pelas alunas por um certo estilo de vida cotidiana mereceu sua apreciação positiva:

tínhamos hábitos saudáveis na mesa, delicados; a alimentação não era coisa do outro mundo, mas ninguém adoeceu de fome. A disciplina não é difícil, se você pensa nos direitos dos outros. Tinha piano de cauda, todo mundo descia, vinha para a sala. 0 ambiente era bom e a mordoma, d. Inácia Lafayette, da família do Colégio Lafayette, era uma pessoa muito competente, educada, fina, fazia toilette para o jantar.

Anna Nava inclusive se percebia como uma representante da "cultura legítima", como disse: em uma escola, você tem que botar pessoas educadas para exemplo das menos dotadas, porque tem de tudo nas escolas. Bourdieu ${ }^{2}$ nos ajuda a melhor compreender esta situação quando diz que as pessoas agem orientadas pelo habitus, o qual reflete as características da realidade social na qual foram socializadas.

Como seria de se esperar, Anna Nava se distinguiu entre as colegas e obteve excelentes notas. As professoras da Escola a avaliaram como aluna muita esforçada, extremamente disciplinada, inteligente e aplicada, enfim, completamente dedicada às suas atividades acadêmicas. Ela não só ocupou o posto de bibliotecária, mas também o prestigioso cargo de presidente do Conselho das Alunas, que tinha por propósito promover a responsabilidade da aluna quanto à sua formação, à manutenção do regime disciplinar do Internato e à preservação da boa imagem da Escola na sociedade. Composto por presidente, secretária e tesoureira, o Conselho discutia os casos de faltas disciplinares das alunas e prescrevia a penalidade, a ser ratificada pela diretora da Escola ${ }^{10}$. 0 comentário de Anna Nava sobre a situação demonstra uma valorização dos bens culturais, condizente com seu capital cultural e social familiar:

eu estudava muito, eu levei o curso a sério, saía pouco, porque não tinha dinheiro, meu salário estava comprometido lá em casa; além disto, eu tinha 
encomendado um piano para minha irmã, na Alemanha; foi o último piano que entrou no Brasil, quando arrebentou a guerra.

0 fechamento dos portos brasileiros aos navios alemães decorreu do rompimento do Brasil com as forças do Eixo (Alemanha, Itália e Japão), em 1942 ${ }^{11}$. Anna continua: não tinha muita possibilidade de cinema, e o rádio estava engatinhando. Mas a Escola tinha uma biblioteca boa e aprazível, convidativa, naquela sombrinha do jardim interno. E, por sorte, eu tive companheiras estudiosas também. De modo que nossa vida era boa. Os estágios eram desgastantes, porque tinha um horário cruel; você trabalhava de sete da manhã ao meio-dia e depois das dezoito até às vinte e duas horas, era de tirar o sangue. Contudo, diz ela, nós todas achávamos aquilo normal, quer dizer, aquilo era o Regulamento e falávamos muito em aprender fazendo, não havia grandes revoltas, não. Esta fala da depoente põe em evidência o "sentido prático" das alunas, em relação ao que podia ser por elas aceito como um modo adequado de viver.

\section{Anna Nava e as diretoras Bertha Pulle, Laís Netto dos Reys e Waleska Paixão}

Suas maiores e melhores lembranças de aluna repousam no período da diretora Bertha Pullen 3 . Diz ela:

eu gostava imensamente e admirava imensamente Miss Pullen, apesar de ser muito rigorosa; ela era protestante, cumpridora, mas ela não fazia proselitismo religioso; ela morava no internato, mas não comia no quarto, porque ela achava que a educação tinha que ser dada também pela presença.

Continua: às quartas-feiras tinha cafezinho na sala de Miss Pullen, ela convidava parte de uma turma; ela tinha vida social intensa, então, ela passava à meia-noite no Hospital São Francisco de Assis (HSFA), só para ver se nós estávamos trabalhando. 0 HSFA fora organizado para servir de campo de práticas para a Escola de Enfermeiras do DNSP, depois Escola Anna Nery ${ }^{7,8,12}$; ele era ligado ao Pavilhão de Aulas da EAN, à Maternidade Thompson Motta e ao Pavilhão Carlos Chagas por um túnel, que passava por baixo da rua Afonso Cavalcanti ${ }^{12}$. Uma vez, Bertha Pullen suspendeu uma aluna 'por falta de amadurecimento para ser enfermeira' porque ela tinha medo de atravessar o túnel na hora do almoço da meia-noite [ceia noturna]. Eessa era uma aluna de uma excelência incomparável (...). Outro exemplo: Miss Pullen encontrou uma aluna provando comida na dietética, era uma aluna modelo, mas a Miss Pullen tirou sua touca por quinze dias. A touca de organdi branco, símbolo de responsabilidade, fazia parte do uniforme das alunas, após o estágio probatório. Em caso de falta no cumprimento de seus deveres, a aluna poderia ser privada de seu uso por tempo determinado, como sanção disciplinar ${ }^{10}$.

Sobre as repercussões do clima político do Estado Novo na EAN, Anna Nava conta: houve uma recepção no Internato para os representantes da Fundação Rockefeller, que foi interrompida por uma 'brigada' de enfermeiras integralistas; elas eram da Saúde Pública, mas a Escola não estava separada delas, não; elas vieram impecavelmente uniformizadas, 'alinhadíssimas', entraram de braço para cima [saudação adotada na década de 30 pela Ação Integralista Brasileira ${ }^{6}$ ]. Nós tivemos muito medo, nós éramos do interior; Miss Pullen teve um medo louco de ser apanhada em uma situação que criasse um caso; ela estava em um país que não era o dela, ela era muito prudente. D. Ruth Barcellos, secretária da Escola, aconselhou-a a telefonar para a Rockefeller, o chefão era o sanitarista americano dr Fred Soper e a Rockefeller tinha escritório na Escola. Eeles foram lá.

A apreciação de Anna Nava é a de que a situação era mais favorável às diretoras americanas, devido ao apoio que elas recebiam da Fundação Rockefeller: Elas cuidavam mais das alunas do que as brasileiras, porque as brasileiras tinham que ir de pratinho na mão nos ministérios (...) as americanas nunca tiveram que fazer esta parte burocrática do fornecimento, porque a Fundação Rockefeller fazia.

Em 1938, LNR ${ }^{6,10}$, ex-diretora da Escola de Enfermagem Carlos Chagas, em BH, na qual Anna Nava com tanto empenho evitara estudar, substituiu Bertha Pullen na direção da EAN. Sobre essa transição ela comenta: o grupo não a aceitou com facilidade; inicialmente, $d$. Laís teve vida muito, muito difícil mesmo, porque ela quis introduzir medidas que absolutamente não cabiam, depois da experiência das alunas com o sistema americano, bastante mais liberal. Por outro lado, completa ela:

d. Laís não foi bem recebida porque Zaíra Cintra Vidal contava com o apoio da maioria das professoras e das alunas para substituir Miss Pullen; d. Zaíra era a alma da Escola (...) Mas d. Laís tinha um irmão no Palácio do Catete, dr. Heleno Moura. Ela era pessoa de renome, não só de família, como também entre as Pioneiras [ $1^{\text {a }}$ turma de diplomadas pela EAN], elas faziam grupo de elite, eram o mesmo que irmãs.

A chegada de LNR reconfigurou o espaço social da EAN. No entanto, a aluna Anna desaprovou o novo estilo de vida implantado pela nova diretora, em flagrante contraste com 0 estilo despojado adotado por Bertha Pullen:

d. Laís morava no internato, numa realeza inconcebível; tinha empregada só para ela, tinha quarto de dormir, tinha sala de jantar, tinha sala de visita, tinha banheiro privativo, tudo no $1^{\circ}$ andar, 
tinha janela para o lado, ela via as alunas saírem no ônibus da Escola para o estágio, tinha janela para frente, um apartamento maravilhoso, o da diretora!

Além do conforto julgado excessivo por Anna Nava, havia também um certo culto à personalidade e uma decidida interferência religiosa nos destinos da Escola: Ela era 'palaciana', ela trouxe um grupo, que a punha num andor, elas andavam de braço dado com ela, mas era um grupo fraco. É fato que na gestão de LNR chegou um grupo de irmãs de caridade para estudar na Escola e a diretora preparou para elas aposentos isolados e capela (justamente onde havia sido o escritório da Rockefeller), mas o comportamento dessas alunas às vezes também causava estranheza à Anna Nava: tinha uma Irmã que descia a escadaria, com sua 'corneta' [peça do hábito, de tecido engomado e armado, que cobria a cabeça das Irmãs] pálida, sem sangue, reclamando que a comida estava fria. Sua opinião é a de que LNR implantou a religião católica na Escola: $d$. Laís era beata e a corte toda dela (...) nós chamávamos 'o grupo do turíbulo' (...) um grupo que achava que ela era de altar e de andor, adulavam-na muito. Segundo ela, tal comportamento trazia vantagens: muitas pessoas receberam 'benéfices' diretamente de d. Laís e eram coisas injustas, porque não eram dadas a todo mundo. Por outro lado, vozes discordantes não eram aceitas: $d$. Laís 'empastelou' o jornalzinho 'A Lâmpada' (editado pelas alunas), porque tinha protesto.

No início dos anos 40, a Reforma Barros Barreto, ao tempo em que ampliou as funções do órgão de saúde pública, extinguiu a Superintendência de Enfermagem, à qual a EAN era subordinada, o que foi recebido com agrado pela Escola: a Escola Anna Nery ficou mais dona de si. No entanto, a partir deste momento, se a superintendente do Serviço de Enfermeiras e a diretora da EAN já não eram amigas, então tornaram-se inimigas; como comenta Anna Nava: eu não sei se elas achavam que d. Laís atuou nesse negócio, eu não seise d. Edith aspirava a ser diretora da Escola Anna Nery, eu sei que elas ficaram inimigas, o que não impediu que Anna Nava sentisse afinidade e admiração por EMF, diplomada nos EUA e porta-voz das enfermeiras americanas, enquanto LNR defendia os interesses da Igreja Católica. Então, diz ela: $d$. Edith foi organizar a Escola de Enfermagem da Universidade de São Paulo (USP), por indicação da Fundação Rockefeller. Eela se cercou de um grupo de professoras de elite, uma elite intelectual, as damas de Toronto [professoras da EEUSP que fizeram o curso de graduação ou de pós-graduação nessa universidade].

Durante a segunda guerra, quando o Exército teve que formar um corpo de enfermeiras, d. Laís não concordou com as condições por ele oferecidas e entrou em contato com a Aeronáutica, na qual se engajaram seis enfermeiras diplomadas, com garantia de treinamento nos EUA e patente de oficial. Quando d. Laís pôs as alunas da Escola para estagiar no Hospital da Aeronáutica, a medida não foi bem recebida pela presidente da Associação de Enfermeiras Diplomadas/Abed, justamente
EMF, já diretora da Escola de Enfermagem da USP, apoiada pela assessora americana Ella Hasenjaeger, do Instituto de Assuntos Interamericanos (IAIA) ${ }^{\text {a }}$. A reclamação era a de que 0 sistema militar faz hierarquia dos doentes, e, para formar alunas, não se pode discriminar. E havia a alegação de que a Abed poderia perder a afiliação ao Conselho Internacional de Enfermeiras. Segundo Anna Nava, a percepção de LNR e de EMF acerca do mundo social divergia radicalmente. Assim, assumiam pontos de vista diferentes, e mesmo antagônicos, "já que os pontos de vista dependem do ponto a partir do qual são tomados, já que a visão que cada agente tem do espaço depende de sua posição nesse espaço" ${ }^{13: 157}$. Segundo Anna Nava: havia uma animosidade declarada e oficializada entre $d$. Edith ed. Laís, e essa animosidade estendia-se também às pessoas da Escola; nós sofríamos um pouco as consequências, mas nós não sabíamos os detalhes.

0 fato de as alunas da EAN, por indicação de sua diretora, prestarem serviços a pessoas influentes, inclusive da família Vargas, como d. Darcy ( $1^{a}$ dama), d. Alzira (filha de Getúlio) e Celina (neta do presidente), suscitava o desagrado da ex-aluna Anna Nava, que fazia comparações desfavoráveis à LNR: esse tipo de prestígio é que as americanas nunca adotaram. No início de 1940, ao final do curso, Anna Nava deixou o internato para morar com sua mãe, que se mudara de BH para o Rio de Janeiro, fixando residência no bairro de Laranjeiras: quando minha família mudou para cá, fiquei externa, porque eu não concordava com a imposição do serviço particular.

Sobre a formação do primeiro quadro de professores privativos da EAN, ela comenta que foi formado por enfermeiras que cuidaram de d. Santinha [1 ${ }^{\text {a }}$ dama no governo Dutra] e por dois médicos, indicados por d. Laís. Também, segundo ela, quando passou a lei proibindo o acúmulo de cargos e a EAN perdeu muitos bons professores, a diretora fez um arranjo com um professor que era da Policlínica do Rio de Janeiro para que ele desse aulas na Escola, e, em contrapartida, a Escola convertia enfermeiras para os serviços dele. Tais estratégias, que se referem a alianças entre agentes que têm por objetivo ocupar ou continuar ocupando posições sociais em determinado campo, não tinham a aprovação de Anna Nava. Ela [LNR] conseguia as coisas, não por mérito, mas por influência política, era uma pena que a gente estivesse subordinada, em tudo entrava o prestígio social".

Ao final da década de 40, como relata Anna Nava, Waleska Paixão começou a vir ao Rio com muita frequência; de repente, d. Waleska, diretora da Escola Carlos Chagas, veio trabalhar na Escola Anna Nery, sem nomeação, nada oficializado. D. Laís estava demonstrando visivelmente que alguma coisa muito séria estava acontecendo com ela, mas como as autoridades têm um comportamento de esconder doença, foi uma coisa muito misteriosa, muito guardada, só um grupo restrito a acompanhava e se dedicava muito a ela. Nós dávamos sangue; quando teve que dar medula, eu não quis. Aínós vimos que ela 
estava grave, ela foi para o Hospital dos Servidores do Estado, onde foi tratada feito uma rainha, porque as chefes lá eram todas enfermeiras diplomadas. E encerra 0 assunto com um comentário breve: o velório foi no salão da Escola.

Após a morte de LNR, em julho de 1950, Waleska Paixão ${ }^{14}$, também católica convicta a quem Anna Nava vira em BH como aluna de enfermagem "esvoaçando véus" e que se formara na Escola preterida por ela, assumiu a direção da EAN. Diz Anna Nava: Ela era uma pessoa em quem você podia confiar. E cita o Prof. Raimundo Moniz de Aragão, Reitor da Universidade (1966-1969): ele disse que ela foi a diretora mais preparada que passou pela Escola, ela falava duas línguas estrangeiras muito bem, francês e inglês, o português impecável.

\section{A trajetória profissional de Anna Nava}

Logo após a formatura de Anna Nava, a professora de enfermagem de saúde pública, Célia Peixoto Alves, que estava prestes a se aposentar, sugeriu à LNR que Anna Nava a substituísse, porém LNR, como detentora do discurso autorizado sobre a nomeação de pessoal para a EAN, recusou o pedido. No entanto, após a aprovação de Anna Nava no concurso para enfermeiras do Departamento Administrativo do Serviço Público (DASP), órgão encarregado da seleção de candidatos aos cargos públicos federais, quando o dr. J.P. Fontenelle, um dos examinadores do concurso, renomado médico sanitarista e jornalista com quem d. Laís havia trabalhado ${ }^{10}$, fez o mesmo pedido, ele foi atendido.

Deste modo, apesar de não fazer parte do grupo de apoio de LNR, Anna Nava detinha uma posição segura no interior da EAN. A boa posição que Anna Nava desfrutava na EAN se estendia ao campo da enfermagem; já em 1944, ou seja, quatro anos após ser diplomada enfermeira, ela começou a participar efetivamente da atual Associação Brasileira de Enfermagem, seja em comissões ou como membro de diversas diretorias.

No entanto, nos seus primeiros tempos de professora de enfermagem, Anna Nava teve que atuar em diversas disciplinas:

A Escola Anna Nery não queria saber se a gente estava preparada para isso ou para aquilo; improvisavam-se as professoras, nós estudávamos muito, mas as alunas sentiam que a gente estava insegura. Quando eu comecei, fazia o que as dirigentes mandavam, comeceilecionando Higiene.

Anna Nava teve até que passar um curto espaço de tempo como professora de enfermagem psiquiátrica:

Eu entrei na Escola, quando não tinha estágio de enfermagem psiquiátrica, antes da lei $775 / 49$, mas infelizmente tive que substituir a [Maria] Dolores Lins (professora especializada que organizou 0 Instituto de Psiquiatria da UB). Também, quando a Lotte (Liesellote Hoeschl Ornellas, enfermeira) nutricionista, professora de Nutrição e Dietética na EAN), foi fazer especialização em Londres, a d. Olga Lacorte (Chefe da Divisão de Ensino, colega de turma de d. Laís e amiga pessoal de Anna Nava) me mandou ensinar Nutrição e eu recusei, aí $d$. Olga falou: - então a Lotte não vail ela exagerou, nãoé?

Assim é que a legitimação da ordem estabelecida tem sobre os agentes 0 efeito de que eles terminem por contribuir para a permanência das relações de dominaçãa ${ }^{3}$.

Mas a divisão do corpo docente da EAN também comportava ambiguidades, como o caso de Olga Lacorte, amiga de LNR e de Anna Nava. Anna Nava comenta: ela foi daquele grupo de apoio à d. Laís, porque d. Laís estava sofrendo muita reação - e foi um apoio feliz. A importância de tal apoio era tanto mais importante porque essa professora encarnava a figura ideal da enfermeira, ou pelo menos da professora da Escola Anna Nery: A beleza ajudava, a posição social ajudava, muita coisa ajudava, aquele carisma que ela sempre teve; nós éramos muito amigas e eu admirava aquele halo, aquela distinção, aquilo era educativo, era um exemplo, ela ensinou Ética e História da Enfermagem. Assim, a reprodução do habitus profissional estava apoiada em mecanismos objetivos, os quais se traduziam em estratégias didático-pedagógicas ${ }^{3}$.

Anna Nava continuou acumulando capital institucionalizado, o que lhe proporcionaria uma posição de cada vez maior distinção no campo da educação em enfermagem. Ao final da segunda guerra, Anna Nava, outra vez por indicação do sanitarista J.P. Fontenelle, obteve uma bolsa de estudos do IAIA para fazer especialização em saúde pública, na Universidade da Pensilvânia/EUA. Sua apreciação deste período é muito elogiosa: tudo muito bem programado; a Interamerican Affairs era muito correta, a bolsa era coisa certa, a Superintendente de onde eu fiz estágio era admirável, os professores eram excelentes, nós tínhamos aula de sociologia em Baltimore, junto com os médicos, também brasileiros. Eu gostei muito do curso, achava formidável!' E ela mais uma vez lamenta uma decisão de LNR: se eu ficasse mais quatro meses, eu teria direito a entrar no mestrado, mas d. Laís não podia abrir mão, tinha pouca gente na Escola. Um desses médicos brasileiros a convidou para trabalhar no Serviço Especial de Saúde Pública, órgão executivo do IAIA, inserido no Ministério da Saúde ${ }^{13}$. Assim, em 1946, ao retornar ao Brasil, Anna Nava trabalhou algum tempo no Vale do Rio Doce, cedida pela EAN. Apesar de estar ganhando "cinco vezes mais", regressou à Escola, por avaliar que não podia pedir demissão de uma coisa certa para uma provável, e também porque o sentido de pertença à EAN era forte.

De volta à Escola, passou a ensinar Enfermagem de Saúde Pública e a trabalhar no Centro de Saúde da Praça da Bandeira, campo de estágio da Escola, com Rosaly Taborda: Olha, nós tínhamos tal poder! Inicialmente foi dificil, mas depois $d$. Rosaly 
conseguiu até colocar o [médico] chefe que ela queria, eu fiquei lá vários anos. Depois, Anna Nava teve uma "experiência maravilhosa" ao trabalhar em um centro de saúde em Niterói com o sanitarista Marcolino Candau, que viria a ser presidente da Organização Mundial de Saúde (OMS) e ministro da Saúde no Brasil: foi um tempo feliz quando eu trabalhei com o dr. Candau, quando eu levava as alunas lá, ele tinha uma deferência muito grande comigo. Em 1946, Anna Nava teve uma segunda oportunidade de afastar-se da EAN, quando o diretor do DASP, dr. Benedito Silva, convidou-a para trabalhar na Organização Mundial de Saúde (OMS): e eu aceitei, pensando que era para a Europa (onde fica a sede da OMS, em Genebra); nos Estados Unidos (onde fica a sede da Organização Pan-Americana de Saúde, em Washington) não me convinha, fiquei cinco meses e meio.

Quando Waleska Paixão assumiu a direção da EAN, Anna Nava, indicada por Olga Lacorte, chefe da Divisão de Ensino, indicou-a à nova diretora para assumir a coordenação da Divisão de Estágios da EAN, em subordinação direta à diretora da EAN. Mas Anna Nava parece não ter apreciado a deferência: não foi o meu melhor tempo, nós tínhamos muitas dificuldades para arranjar bons hospitais para os estágios, e, por outro lado, eu queria voltar para a Saúde Pública. Quando a nova diretora indicou Anna Nava para substituí-la em seus impedimentos, a apanhou de surpresa: eu era amiga recente de d. Waleska, não sei se foi indicação de d.Olga, porque nós éramos amigas; também pode ser porque eu a ajudei muito na sua adaptação à Escola, com as pessoas e com os problemas, mas eu não gosto de administração.

Contudo, o vasto capital cultural de Waleska Paixão e sua personalidade conciliadora foram decisivos para conquistar a admiração de Anna Nava. Isto certamente contribuiu para que ela aceitasse tal encargo e dele tratasse com tanto empenho, ainda mais porque essa diretora viajava muito, e Anna Nava frequentemente se via às voltas com os problemas da Escola. Mas reitera seu desagrado: sónão foi bom porque eu não gostava muito do trabalho, eu queria voltar para a Saúde Pública. E completa: substituí $d$. Waleska quinhentos milhões de vezes, talvez por isto eu seja a única vice-diretora que não chegou à diretora, porque eu fiquei escaldada!

No final dos anos 60, Anna Nava, ao ser indicada para lecionar a disciplina História da Enfermagem, a qual era ministrada pela diretora da EAN, Waleska Paixão, teve mais uma vez reconhecido seu capital cultural e social, pois essa disciplina costumava ser atribuída às porta-vozes da Enfermagem, que tinham um discurso autorizado sobre a profissão. Meses antes de sua aposentadoria, Anna Nava deu mais uma demonstração de sua consciência histórica. Como conta Cecília Pecego Coelho ${ }^{10}$, ex-diretora da Escola, Anna Nava e Madalena Werneck, instrutora aposentada, fizeram a organização preliminar do Arquivo Histórico da EAN. Entre outras coisas, elas classificaram e prepararam mais de mil fotos para o manuseio em arquivo, além de identificar a grande maioria dos fotografados e a época das fotos. Tais providências em muito favoreceram a criação, em 1993, do Cedoc/EEAN/ UFRJ.

\section{Anna Nava, por ela mesma}

Personalidade discreta e reservada, ela se mostrava, no entanto, orgulhosa de sua ascendência familiar:

Eu sou de uma familia que sofreu para libertar o país: uns eram republicanos, outros eram monarquistas. Meu trisavô era irmão de d. Bárbarab, a heroína da Confederação do Equador, ele foi trucidado, o filho dele morto com revolver no coração, minha bisavó nasceu no mato. De modo que eu sou descendente de um mártir. Minha familia mudou até de nome por causa do nacionalismo. Jaguaribe é nome inventado, o rio Jaguaribe era aquela corrente que ia salvar o nordeste da seca. $A$ avó do historiador Helio Jaguaribe era irmã do meu avô.

Na vida profissional, Anna Nava guardou a mesma altivez: Eu toda vida fui muito cerimoniosa, nunca peguei em turíbulo, nunca viajei às custas da Escola para lugar nenhum, nunca tive uma gratificação e nunca tive 40 horas [gratificação por horário integral].

Também se nota uma indisfarçável consciência de distinção cultural de família e seus relacionamentos: Nós em casa nos entretínhamos com música e leitura, de manhã à noite. Além disso, a professora Anna se orgulhava de saber selecionar suas amizades: minha mãe dizia que eu era a criatura mais hábil do mundo para escolher amigas. E exemplifica: a Irene Zoffolli, minha colega de quarto, era a 'Rui Barbosa' da minha classe, nós estudávamos juntas; ela trabalhou na saúde pública e também no hospital Carlos Chagas (em Marechal Hermes) onde meu irmão era diretor. Também relata ocasiões em que seu capital social lhe permitiu lançar mão de suas relações pessoais para resolver problemas da EAN. Diz ela:

uma vez eu fui à casa de Carlos Chagas [Filho]', pedir para ele me levar para falar com o Deolindo Couto (reitor da UB), para que ele autorizasse o pagamento dos empenhos, para que ofornecimento da alimentação no Internato não fosse suspenso: eram oito horas da noite quando o 'Carlinhos' Chagas me levou à Escola de volta.

\section{Ela conta outra passagem:}

eu introduzi a Glete de Alcântara no gabinete do ministro Capanema, por intermédio de Carlos Drumond de Andrade. Ela estava com o processo de reconhecimento da Escola de Ribeirão Preto (da 
USP) encravado e eu fui com ela lá: ela ficou boba com o prestígio, mas não era propriamente da Escola Anna Nery, era porque eu vio 'Carlos' no lombo de burro, no tempo em que não tinha estrada de ferro, eu era meninota, então eu disse: não Glete, não é prestígio da Escola Anna Nery não, é meu.

Prezava muito a fidelidade: Eu acho tão confortante você trabalhar com pessoas em quem você pode confiar! Uma vez, na secretaria da Escola, fizeram uma manifestação para mim, e a coisa que eu mais gostei de ouvir foi que todas falaram em uníssono: "nós confiamos na senhora". A coisa que você mais deseja é ser acreditada. É uma necessidade humana.

\section{CONSIDERAÇÕES FINAIS}

Anna Nava aposentou-se em 1977, depois de quase quarenta anos de relevantes serviços prestados à EAN e à causa da enfermagem. Seu amor à EAN e à profissão é perene: Quando eu terminei o curso, eu gostava tanto da Escola que achei que tinha um compromisso! Nós temos o compromisso de vigiar os valores que a Escola plantou em nós. Eu gostava da Escola, como eu gosto da Escola! Desde o dia 20 de maio de 2005 não contamos com a presença física de Anna Nava. Vale registrar a coincidência da data do passamento da professora Anna Nava (20 de maio) com o de outra Anna, aquela que nomeia a Escola Anna Nery.

Na fala de Anna Nava é marcante a permanência de suas características intelectuais e de personalidade, das quais derivava um discurso autorizado acerca dos encaminhamentos das situações que se apresentavam em seu espaço de atuação. Seus gestos e as suas palavras tiveram ressonância em seu espaço profissional, pela acuidade de suas observações e por

\section{REFERÊNCIAS}

1 Christo MCV. A Europa dos pobres: Juiz de Fora na Belle Époque Mineira. Juiz de Fora (MG): UFJF; 1994.

2 Nogueira MA, Nogueira CMM. Bourdieu \& a educação. Belo Horizonte(MG): Autêntica; 2004.

3 Bourdieu P. Coisas ditas. São Paulo(SP): Brasiliense; 1990.

4 Nava AJS. Depoimento concedido à Suely de Souza Baptista em setembro e outubro de 2003. Rio de Janeiro(RJ): Acervo de História Oral/Cedoc/EEAN/UFRJ.

5 Lima VR, organizadora. Getúlio: uma história oral. Rio de Janeiro(RJ): Record; 1986.

6 Almeida Filho AJ. A Escola Anna Nery no front do campo da educação em enfermagem e o (re)alinhamento de posições de poder:19311949. [tese de doutorado]. Rio de Janeiro (RJ): Escola de Enfermagem Anna Nery/UFRJ; 2004.

7 Sauthier J, Barreira IA. As enfermeiras norte-americanas e o ensino da enfermagem na capital do Brasil (1921-1931). Rio de Janeiro(RJ): EEAN/UFRJ; 1999. suas críticas incisivas. A vigilância crítica por ela exercida era em muito apoiada pelo grande volume de capital de todas as ordens de que era legítima possuidora.

Sua apreciação sobre as gestões das três diretoras de que trata o presente estudo, à época da gravação do depoimento, contrasta com a imagem pública por elas deixada na maioria das professoras e alunas. Bertha Pullen, última diretora americana da EAN, é lembrada como profissional competente, de caráter a toda prova, mas por vezes rígida e pouco hábil. Ao contrário, LNR, com seu carisma e suas alianças políticas, é figura muito exaltada, competindo em prestígio com Clara Louise Kieninger, a primeira diretora americana da Escola. E Waleska Paixão é a figura menos sujeita a controvérsias, por seu espírito conciliador, faceta de seu caráter reconhecido quando foi presidente da Abed. A apreciação de Anna Nava é diferente. De LNR não guarda boa recordação e faz críticas severas à sua gestão. E em que pese sua admiração por Waleska Paixão: admiro a inteligência, o espírito de justiça, o caráter, admiro a pessoa trabalhando, às vezes, em estado de debilidade de saúde, admiro a dedicação dela, sua avaliação é definitivamente favorável à americana Bertha Pullen, eu acho que nenhuma brasileira chegou aos pés de Miss Pullen.

0 trabalho ora apresentado deve-se a mais um ato de boa vontade da professora Anna Jaguaribe da Silva Nava, que nos concedeu, no ano de 2003, o privilégio de com ela conversar, por várias horas e em diferentes momentos, do alto de seus 93 anos de idade, acerca de questões do ensino da enfermagem, do exercício profissional, das relações entre as pessoas e das circunstâncias de sua vida.

Suas realizações estão presentes na História da Enfermagem Brasileira. Por tudo isto, e ainda faltando muito, com este artigo também prestamos uma homenagem à memória da ilustre mestra.

8 Santos TCF, Barreira IA. 0 poder simbólico da enfermagem norteamericana no ensino da enfermagem na capital do Brasil (19281938). Rio de Janeiro(RJ): EEAN/UFRJ; 2002.

9 Carvalho AC. Associação Brasileira de Enfermagem:1926-1976documentário. Brasília (DF): ABEn; 1976.

10 Coelho CP. Escola Anna Nery: sua história, nossas memórias. Rio de Janeiro (RJ): Cultura Médica; 1997.

11 D'Araujo MC, organizadora. As instituições da Era Vargas. Rio de Janeiro(RJ): UERJ/FGV; 1999.

12 Silva Junior OC. Do Asylo da Mendicidade ao Hospital Escola São Francisco de Assis: a mansão dos pobres. Rio de Janeiro(RJ): Papel Virtual; 2000.

13 Campos ALV. Políticas Internacionais de Saúde na Era Vargas: o Serviço Especial de Saúde Pública (1942-1960). Rio de Janeiro(RJ): Fiocruz; 2006.

14 Secaf V, Costa HCBV. Enfermeiras do Brasil: história das pioneiras. São Paulo(SP): Martinari; 2007. 
15 Fundação Getúlio Vargas-FGV. Centro de Pesquisa e Documentação de História Contemporânea do Brasil. Dicionário histórico-biográfico brasileiro: 1930-1983. Rio de Janeiro(RJ): FGV; 1984. Melo, Arnon de; p.2179.
16 Del Priore M, Venâncio RP. 0 livro de ouro da história do Brasil. Rio de Janeiro(RJ): Ediouro; 2001.

17 Chagas Filho C. Cultura e ciência. Rio de Janeiro (RJ): Fundação Universitária José Bonifácio; 1989.

\section{Notas}

a Instituto de Assuntos Interamericanos (IAIA), ou seja the Interamerican Affairs Institute - responsável pelo Programa Cooperativo de Saúde e Saneamento na América Latina, instituído durante a $2^{\mathrm{a}}$ guerra (1942). 0 IAIA teve 181 técnicos americanos atuando no Brasil ${ }^{13}$.

b Bárbara de Alencar (1760-1823) envolveu-se, com dois de seus filhos e um de seus irmãos, nas conspirações republicanas deflagradas no nordeste em 1817 (Revolução Pernambucana) e em 1824 (Confederação do Equador), que sofreram repressão violenta do governo imperial. Seu filho Tristão de Alencar Araripe morreu em combate ${ }^{16}$.

'Carlos Chagas Filho nasceu no Rio de Janeiro em 1910, filho do cientista Carlos Chagas. Formou-se na Faculdade Nacional de Medicina (FNM). Estagiou no Instituto Oswaldo Cruz e no hospital São Francisco de Assis. Tornou-se catedrático concursado da FNM aos 26 anos. Em 1945 criou o Instituto de Biofísica da UB. Colaborou na fundação do CNPq, do qual foi conselheiro. Ocupou vários cargos científicos ligados à Organização das Nações Unidas (ONU). Foi presidente da Academia Brasileira de Ciências e da Academia Pontifícia de Ciências ${ }^{17}$. 